\title{
Taurine Release from Brain Slices in Thioacetamide-Induced Hepatic Encephalopathy in Rats
}

\author{
URSZULA WYSMYK, ${ }^{1,2}$ SimO S. OJA, ${ }^{1}$ AND PIRJO SARANSAARI ${ }^{*, 1}$ \\ 'Tampere Brain Research Center, Department of Biomedical Sciences, \\ University of Tampere, Box 607, SF-33101 Tampere, Finland, \\ and ${ }^{2}$ Medical Research Centre, Polish Academy of Sciences, \\ 3 Dworkowa Str., 00-784 Warsaw, Poland
}

Received May 15, 1990; Accepted October 29, 1990

\begin{abstract}
The possible involvement of taurine in the pathogenesis of hepatic encephalopathy was studied in rats injected with thioacetamide. Spontaneous release of exogenous labeled taurine was not affected in any brain area studied, but the potassium-stimulated release was enhanced in the striatum in thioacetamide-treated rats. High concentrations of ammonium ions also evoked greater release of taurine from striatal slices in rats with thioacetamide-induced hepatic encephalopathy.
\end{abstract}

Index Entries: Hepatic encephalopathy; taurine release; thioacetamide; potassium; ammonia; GABA; brain slices; striatum; rats.

\section{ABBREVIATIONS}

GABA: $\gamma$-aminobutyric acid HE: hepatic encephalopathy
Hepes: N-2-hydroxyethylpiperazine- $\mathrm{N}^{\prime}$-2-ethanesulphonic acid

*Author to whom all correspondence and reprint requests should be addressed. 


\section{INTRODUCTION}

Abnormalities in neurotransmission have been widely assumed to underlie disturbances in the function of the central nervous system in hepatic encephalopathy (HE). Increased levels of $\gamma$-aminobutyric acid (GABA) in the brain or an augmentation of inhibition mediated by GABA receptors have been suggested as causal factors in the pathogenesis of hepatic coma-the terminal stage of HE (Blitzer et al., 1978; Pappas et al., 1984; Zieve, 1987). However, in some recent studies very slight changes, if any at all, were found in the brain levels of GABA in $\mathrm{HE}$, indicating only minor involvement of GABA (Butterworth and Giguere, 1986; Butterworth et al., 1987). This prompted us to focus on the possible involvement of taurine in HE. This sulfur-containing amino acid abounds in the brain, is structurally related to GABA, and shares some of its inhibitory properties. Taurine is particularly enriched in synaptic structures (De Belleroche and Bradford, 1973; Kontro et al., 1980; Huxtable, 1982; Walz and Allen, 1987) and has been considered an inhibitory neuromodulator (Cooper at al., 1982; Oja and Kontro, 1983; Kontro et al., 1984; Sakai et al., 1985).

Ammonia is a main factor proposed to be involved in the pathomechanism of HE (Zieve, 1987). The concentration of ammonia is elevated in the blood and central nervous system of most patients with clinical $\mathrm{HE}$ and animals with experimental HE (Butterworth et al., 1987). It has been shown that ammonia can affect the membrane potential and excitability of neurons (see Cooper and Plum, 1987) and astrocytic transport of amino acid neurotransmitters (Norenberg et al., 1985), although the mechanism of the toxic effect of ammonia is not wholly established. We analyzed changes in the potassium-evoked release of taurine from various structures of the brain in rats with thioacetamide-induced HE. The striatum appeared to be the most sensitive brain area in HE and hence the effects of different concentrations of ammonium chloride on the release of taurine from striatal slices were assessed as well.

\section{MATERIALS AND METHODS}

Thioacetamide $(300 \mathrm{mg} / \mathrm{kg}$ ) was daily injected intraperitoneally into adult male Wistar rats ( $200 \mathrm{~g}$ ) on three successive days in order to induce a precomatose stage. This hepatotoxic model of subacute hepatic encephalopathy is accompanied by elevated blood and brain ammonia, increased blood phenols and changes in other biochemical and physiological parameters characteristic of HE (Hilgier et al., 1983; Albrecht and Hilgier, 1984; Hilgier et al., 1985; Pluta and Albrecht, 1984, see Albrecht et al., 1988 for further references).

Slices $0.5 \mathrm{~mm}$ thick were manually cut with a tissue slicer of StadieRiggs type from the cerebral cortex, striatum, cerebellum, and pons. The 
slices were preincubated for $30 \mathrm{~min}$ with $10 \mu \mathrm{M}\left[{ }^{3} \mathrm{H}\right]$ taurine in standard Krebs-Ringer-Hepes medium (in $\mathrm{mM} ; \mathrm{NaCl} 127, \mathrm{KCl} 5, \mathrm{CaCl}_{2} 0.75$, $\mathrm{MgSO}_{4} 1.3, \mathrm{Na}_{2} \mathrm{HPO}_{4} 1.3$, Hepes 15, NaOH 11, D-glucose 10, pH 7.4) at $37^{\circ} \mathrm{C}$ under $\mathrm{O}_{2}$. They were then rinsed with nonradioactive medium and finally superfused at a rate of $0.25 \mathrm{~mL} / \mathrm{min}$ for $50 \mathrm{~min}$ at $37^{\circ} \mathrm{C}$ in a system in which freely floating agitated slices were kept in a small volume $(0.25$ $\mathrm{mL}$ ) of preoxygenated medium. This method has been shown to ensure sufficient thorough oxygenation and to preserve the viability of the preparations, as reflected by maintenance of normal ion gradients, structural integrity, and characteristics of transmitter release (Korpi and Oja, 1983, 1984; Pitkänen et al., 1985). The effluent samples were pooled during the first $20 \mathrm{~min}$ and subsequent 2 -min fractions $(0.5 \mathrm{~mL})$ were collected into scintillation vials with a fraction collector (Gilson TDC 220). At $30 \mathrm{~min}$, the standard superfusion medium was abruptly changed to another medium containing $50 \mathrm{mM} \mathrm{K}{ }^{+}$ions (stimulated efflux) or left unchanged (spontaneous efflux). Striatal slices from both control and thioacetamide-treated rats were also subjected to $\mathrm{NH}_{4} \mathrm{Cl}\left(\mathrm{NH}_{4}{ }^{+}\right.$ions) at concentrations of $0.5,10$, or $50 \mathrm{mM}$; in some experiments in medium supplemented with $50 \mathrm{mM} \mathrm{K} \mathrm{K}^{+}$. The cationic balance was then obtained by equimolar reduction of $\mathrm{Na}^{+}$. The radioactivity in the slices and the 2-min fractions of superfusion medium was assayed by scintillation spectrometry.

The efflux rate constants of taurine for the time intervals of 20-30 min $\left(k_{1}\right)$ and 34-50 min $\left(k_{2}\right)$ were computed as negative slopes of the linear regression lines fitted to the logarithm of the radioactivity remaining in the slices vs superfusion time (Korpi and Oja, 1979). The constants $k_{2}$ are given as percentages of the corresponding $k_{1}$ values for each slice in order to minimize interexperimental variation. The statistically significant differences were detected by analysis of variance. As an a priori test, the variance ratios for the corresponding control and thioacetamide-treated groups were calculated and compared to the theoretical 5 and 1 percentage points.

\section{RESULTS}

The spontaneous efflux of taurine from the slices of all brain structures studied was slow, about $97-98 \%$ of the initial radioactivity remaining in the slices after superfusion. Potassium stimulation $(50 \mathrm{mM} \mathrm{K}$ ) from 30 min onwards induced a slow but fairly stable release of taurine in the cerebral cortex, pons (data not shown) and striatum (Fig. 1). The stimulation was only small in magnitude in the cerebellum. The range of average potassium stimulation of taurine efflux was from 1.15 to 1.85fold in control rats when compared to spontaneous release during the same superfusion period (Table 1). Thioacetamide-induced HE did not change the basal release of taurine. The potassium-stimulated release of taurine was enhanced only in the striatum in HE (Table 1). 


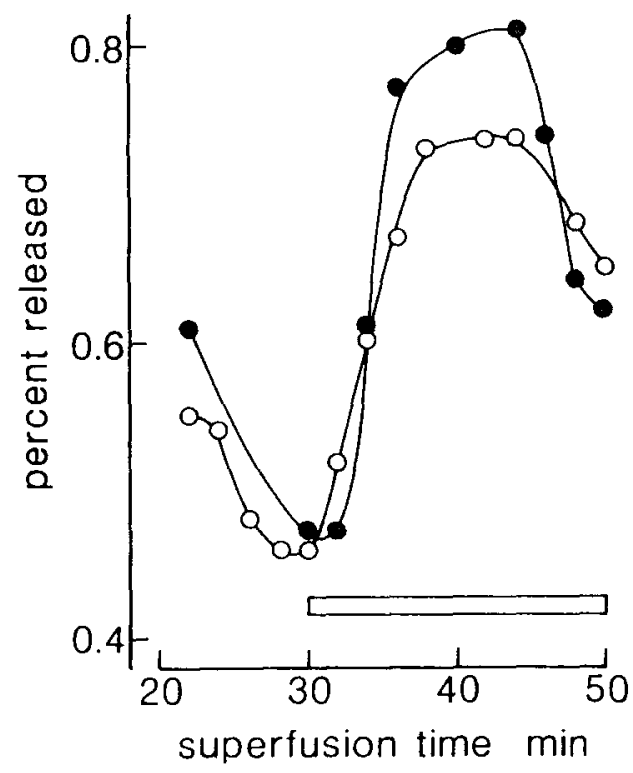

Fig. 1. Taurine release from striatal slices from control $(O)$ and thioacetamidetreated $(\bullet)$ rats. Experimental details as in Table 1 . The period of potassium stimulation $(50 \mathrm{mM})$ is indicated by the bars. Individual representative experiments are shown.

The efflux rate constants $\left(k_{2}\right)$ for taurine in striatal slices from control rats increased proportionally to the concentration of ammonium ions in superfusion medium, being $209 \%$ at the $50-\mathrm{mM} \mathrm{NH}_{4}{ }^{+}$concentration (Table 2). The response to the combined effect of the $50-\mathrm{mM}$ concentration of both $\mathrm{K}^{+}$and $\mathrm{NH}_{4}{ }^{+}$was significantly less pronounced. The stimulation of taurine release by ammonium ions in thioacetamide-treated rats was similarly dose-dependent and even more pronounced than in control rats. Also in the treated rats the responses to the combination of high concentrations of $\mathrm{K}^{+}$and $\mathrm{NH}_{4}^{+}$ions were greatly attenuated when compared to those elicited by $\mathrm{NH}_{4}{ }^{+}$or $\mathrm{K}^{+}$ions alone.

\section{DISCUSSION}

The present results show that the spontaneous efflux of taurine is not affected in HE in any of the brain structures studied. The magnitude of potassium-stimulated release varied in different brain areas, being smallest in the cerebellum, as noted in earlier reports (Okamoto and Namina, 1978; Korpi et al., 1981). The explanation why an increase in potassium-stimulated release of taurine was only discernible in striatal 
Table 1

Fractional Efflux Rate Constants of Taurine in Rat Brain Slices

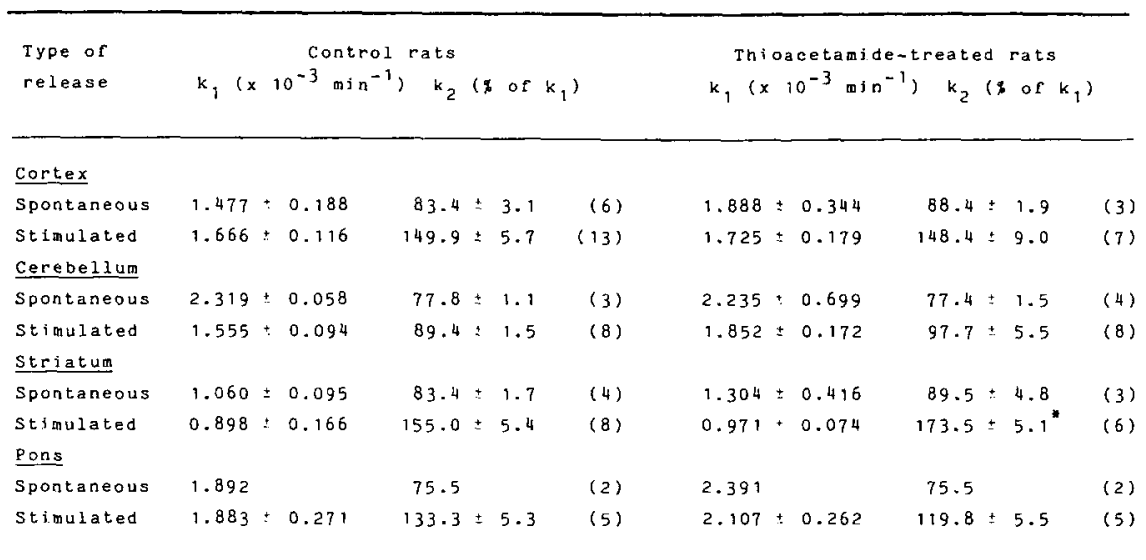

The slices were preloaded with $10 \mu \mathrm{M}\left[{ }^{3} \mathrm{H}\right]$ taurine for $30 \mathrm{~min}$ at $37^{\circ} \mathrm{C}$ in Krebs-Ringer-Hepes medium ( $\mathrm{pH} 7.4$ ) and then superfused for $50 \mathrm{~min}$ with the same medium. At $30 \mathrm{~min}, 50 \mathrm{mM} \mathrm{Na}{ }^{+}$ions were replaced by $50 \mathrm{mM} \mathrm{K} \mathrm{K}^{+}$ions (stimulated release) or the medium was left unchanged (spontaneous release). The rate constants $k_{1}$ refer to the superfusion period of 20-30 min and the constants $k_{2}$ to the period of $34-50 \mathrm{~min}$. Number of experiments in parentheses. Statistically significant difference from the control: ${ }^{*} \mathrm{p}<0.05$.

Table 2

Effect of Ammonium Ions on the Fractional Efflux Rate Constants of Taurine from Rat Striatal Slices

\begin{tabular}{|c|c|c|c|c|}
\hline \multirow{2}{*}{$\begin{array}{l}\text { Substance present } \\
\text { from } 30 \text { to } 50 \text { min } \\
\text { (mM) }\end{array}$} & \multicolumn{2}{|c|}{ Control rats } & \multicolumn{2}{|c|}{ Thioacetamide-treated rats } \\
\hline & $k_{2}(\%$ of & $\left.\mathrm{k}_{1}\right)$ & $k_{2}\left(\begin{array}{l}* \\
\text { of } \\
k_{1}\end{array}\right)$ & \\
\hline $\mathrm{NH}_{4}^{+} 0.5$ & $73.8 \pm 2: 9$ & (5) & $78.9 \pm 3.9$ & \\
\hline $\mathrm{NH}_{4}^{4}+10$ & $121.9 \pm 4.4$ & (4) & $132.4 \pm 2.3$ & \\
\hline $\mathrm{NH}_{4}^{+}+50$ & $209.9 \pm 23.6$ & $(10)$ & $323.0 \pm 30.6^{* *}$ & \\
\hline $\mathrm{NH}_{4}^{+}+50+\mathrm{K}^{+} 50$ & $134.2 \pm 10.4$ & $(10)$ & $239.3 \pm 35.7^{* *}$ & \\
\hline $\mathrm{NH}_{4}+10+\mathrm{K}^{+} 50$ & $110.0 \pm 6.6$ & (5) & $115.2 \pm 8.1$ & \\
\hline $\mathrm{NH}_{4}^{+} 10+\mathrm{K}^{+} 50^{\mathrm{a}}$ & $124.1 \pm 2.8$ & (5) & $121.5 \pm 10.5$ & \\
\hline $\mathrm{K}^{+} 50$ & $155.0 \pm 5.4$ & (8) & $173.5 \pm 5.1^{*}$ & \\
\hline
\end{tabular}

${ }^{a} \mathrm{NH}_{4}{ }^{+}$was present from the beginning of the superfusion.

Statistically significant differences from the corresponding control: ${ }^{*} \mathrm{p}<0.05$, ${ }^{* *} \mathrm{p}<0.01$.

slices in HE is probably rather complex owing to mutual interactions of both excitatory and inhibitory neurotransmitters. Taurine is not generally considered a classical transmitter, but mounting evidence suggests that it may interfere with the function of the inhibitory neurotransmitter GABA (Namima et al., 1983; Malminen and Kontro, 1986; Kontro and Oja, 1990) and may thence affect neuronal excitability in HE. Although studies on 
the contribution of GABA to the pathogenesis of HE have yielded rather controversial data, a recent study has indicated a significant inhibition of potassium-stimulated release of $\left.{ }^{3} \mathrm{H}\right] \mathrm{GABA}$ in striatal synaptosomes from rats in carbon tetrachloride-induced hepatic coma (Diaz-Munoz and Tapia, 1988). The simultaneously observed enhancement in the uptake of GABA should cause a decrease in the efficacy of the inhibitory function of GABA. The potentiation of potassium-evoked release of taurine may result in increased occupation of synaptic receptor sites of GABA by taurine. This appears plausible in the light of evidence available that taurine interferes with the binding of GABA to both postsynaptic $G_{A B A}$ and $\mathrm{GABA}_{\mathrm{B}}$ receptors (Greenlee et al., 1978; Hitzemann and Loh, 1978; Kontro and Oja , 1990) and may modulate the function of presynaptic GABA autoreceptors (Namima et al., 1983; Medina and De Robertis, 1984; Malminen and Kontro, 1986). Moreover, it has been recently shown that in HE taurine is increased to levels which in vitro markedly inhibit the binding of GABA (Maddison et al., 1990).

The characteristic morphological changes indicate that astrocytes are the cell type primarily affected in HE (Norenberg, 1981). In chronic liver diseases, such as $\mathrm{HE}$, the protoplasmic astrocytes increase in number and size, taking on a characteristic appearance identified as the Alzheimer Type II astrocyte with an enlarged nucleus and a thin rim of surrounding cytoplasm (Zieve, 1982). The astrocytes show likewise a whole spectrum of biochemical abnormalities, such as changes in amino acid neurotransmitters and in transport of mono- and divalent ions (see Albrecht et al., 1988). Furthermore, swelling of astrocytes is a salient feature in a number of pathological conditions, HE included (Kimelberg and Ransom, 1986). Potassium stimulation also increases the cell volume, this being accompanied by the release of taurine (Pasantes-Morales and Schousboe, 1989; Martin et al., 1990). It is thus conceivable that striatal astrocytes contribute to the increase in stimulated release of taurine in HE. Striatal astrocytes may also be more sensitive to swelling in HE and release more taurine in high-potassium media. Pertinent to the aforementioned discussion are observations that release of taurine can be elicited from astrocytes by activation of their $\beta$-adrenergic receptors (Van Calker and Hamprecht, 1981; Shain et al., 1986). An activation of $\beta$-adrenergic receptors in response to swelling of cerebral cortex slices (Bourke et al., 1983) and ammonia-induced aberration of the adrenergic cAMP-system in primary astrocytes (Lisowsky et al., 1986) suggest that ammonia in HE may affect the volume regulation of astrocytes and increase the release of taurine from striatal slices in vitro.

We cannot rule out the possibility that the neuronal elements in the striatum are also affected in $\mathrm{HE}$, although likely not so much as the glial cells. Dopaminergic axons make direct synaptic connections with GABAergic neurons in the rat striatum (Kubota et al., 1987). The striatal release of GABA may be differentially regulated by $D_{1}$ and $D_{2}$ receptors, the latter being responsible for inhibitory modulation (Reid et al., 1990). 
Even low concentrations of ammonia evoke release of dopamine from rat cerebral synaptosomes (Erecińska et al., 1987). The increased release of taurine in $\mathrm{HE}$ may be compensatory to the diminished release of GABA in maintenance of synaptic inhibition in the striatum.

Electrophysiological studies have demonstrated that ammonia affects the excitability of neuronal membranes by shifting inhibitory postsynaptic potentials toward the resting potential and slowing extrusion of $\mathrm{Cl}^{-}$from neurons (Lux et al., 1970). The effects of $\mathrm{NH}_{4}{ }^{+}$ions also partially mimic those of $\mathrm{K}^{+}$or $\mathrm{Na}^{+}$ions (see Cooper and Plum, 1987). The attenuation of the release of taurine in the presence of both high $\mathrm{K}^{+}$ and $\mathrm{NH}_{4}{ }^{+}$may reflect decreased synaptic excitation (Raabe, 1989), which may be due to $\mathrm{K}^{+}$-like ionic properties of $\mathrm{NH}_{4}{ }^{+}$and/or inhibition of $\mathrm{K}^{+}$ uptake into astrocytes (Norenberg et al., 1985). A prolonged exposure to $\mathrm{NH}_{4}{ }^{+}$results in suppression of the frequency of spontaneous action potentials, increase of $\mathrm{Na}^{+}$, and decrease of $\mathrm{K}^{+}$intracellularly in slices (Benjamin et al., 1978). The potassium-stimulated release of taurine may hence decrease in the presence of $\mathrm{NH}_{4}{ }^{+}$. We cannot thus exclude the possibility that some of the $\mathrm{NH}_{4}{ }^{+}$-induced release of taurine originates from neurons. The question must be settled with studies on isolated or cultured cells of glial and neuronal origins.

\section{ACKNOWLEDGMENTS}

The expert technical assistance of Ms. Marja Vähäsarja and Ms. Paula Kosonen and the financial support of the Academy of Finland and the Polish Academy of Science, grant no. 10.4.05.1.1, are gratefully acknowledged.

\section{REFERENCES}

Albrecht J. and Hilgier W. (1984) Brain carbonic anhydrase activity in rats in experimental hepatogenic encephalopathy. Neurosci. Lett. 45, 7-10.

Albrecht J., Hilgier W., Lazarewicz J. W., Rafalowska U., and Wysmyk-Cybula U. (1988) Astrocytes in acute hepatic encephalopathy: Metabolic properties and functions, in Neurology and Neurobiology (Norenberg M.D., Hertz L. and Schousboe A., eds.), vol. 39, pp. 465-476, Alan R. Liss, New York.

Benjamin A. M., Okamoto K., and Quastel J. H. (1978) Effect of ammonium ions on spontaneous action potentials and contents of sodium, potassium, ammonium and chloride ions in brain in vitro. J. Neurochem. 30, 131-143.

Blitzer B., Waggoner J. G., Jones E. A., Cralnick H. R., Towne D., Butter J., Weise V., Kopin I. J., Walters I., Teychenne P. F., Goodman D. G., and Berk P. D. (1978) A model of fulminant hepatic failure in the rabbit. Gastroenterology 74, 664-671.

Bourke R. S., Kimelberg H. K., Dazé M., and Church G. (1983) Swelling and ion uptake in cat cerebrocortical slices: Control by neurotransmitters and ion transport mechanisms. Neurochem. Res. 8, 5-24. 
Butterworth R. F. and Giguere J. F. (1986) Cerebral amino acids in portalsystemic encephalopathy: Lack of evidence for altered $\gamma$-aminobutyric acid (GABA) function. Metab. Brain Dis. 1, 221-228.

Butterworth R. F., Levoie J., Giguere J. F., Layrargues G. P., and Begeron M. (1987) Cerebral GABA-ergic and glutamatergic function in hepatic encephalopathy. Neurochem. Path. 6, 131-144.

Cooper J. R., Bloom F. E., and Roth R. H. (1982) The Biochemical Basis of Neuropharmacology, pp. 501-533, Oxford University Press, New York.

Cooper A. J. L. and Plum F. (1987) Biochemistry and physiology of brain ammonia. Physiol. Rev. 64, 440-519.

De Belleroche J.S. and Bradford H.F. (1973) Amino acids in synaptic vesicles from mammalian cerebral cortex: A reappraisal. J. Neurochem. 21, 441-451.

Diaz-Munoz M. and Tapia R. (1988) Regional brain GABA metabolism and release during hepatic coma produced in rats chronically treated with carbon tetrachloride. Neurochem. Res. 13, 37-44.

Erecińska M., Pastuszko A., Wilson D. F., and Nelson D. (1987) Ammoniainduced release of neurotransmitters from rat brain synaptosomes: Differences between the effects on amines and amino acids. J. Neurochem. 49, 1258-1265.

Greenlee D. V., Van Ness P. C., and Olsen R. W. (1978) Endogenous inhibitor of GABA binding in mammalian brain. Life Sci. 22, 1653-1662.

Hilgier W., Albrecht J., and Krasnicka Z. (1983) Thioacetamide-induced hepatic encephalopathy in the rat. Preliminary morphological and biochemical observations. Neuropat. Pol. 21, 487-494.

Hilgier W., Zitting A., and Albrecht J. (1985) The brain octopamine and phenylethanolamine content in rats in thioacetamide-induced hepatogenic encephalopathy. Acta Neurol. Scand. 71, 195-198.

Hitzemann R. J. and Loh H. H. (1978) A comparison of GABA and $\beta$-alanine transport and GABA membrane binding in the rat brain. J. Neurochem. 30, 471-477.

Huxtable R. J. (1982) Taurine and the heart. Adv. Exp. Med. Biol. 139, 161-164.

Kimelberg H. K. and Ransom B. R. (1986) Physiological and pathological aspects of astrocytic swelling, in Astrocytes (Fedoroff S. and Vernadakis A., eds.), pp. 129-166, Academic Press, New York.

Kontro P. and Oja S. S. (1990) Interactions of taurine with GABA $\mathrm{G}_{\beta}$ binding sites in mouse brain. Neuropharmacology 29, 243-247.

Kontro, P., Marnela, K.-M., and Oja, S.S. (1980) Free amino acids in the synaptosome and synaptic vesicle fractions of different bovine brain areas. Brain Res. 184, 129-141.

Kontro P., Korpi E. R., Oja O. S., and Oja S. S. (1984) Modulation of noradrenaline uptake and release by taurine in rat cerebral slices. Neuroscience 13, 663-666.

Korpi E.R. and Oja S. S. (1979) Efflux of phenylalanine from rat cerebral cortex slices as influenced by extra- and intracellular amino acids. I. Neurochem. 32, 789-796.

Korpi E. R. and Oja S. S. (1983) Characteristics of taurine release from cerebral cortex slices by sodium-deficient medium. Brain Res. 289, 197-204.

Korpi E. R. and Oja S. S. (1984) Comparison of two superfusion systems for study of neurotransmitter release from rat cerebral cortex slices. J. Neurochem. 43, 236-242. 
Korpi E. R., Kontro P., Nieminen K., Marnela K.-M., and Oja S. S. (1981) Spontaneous and depolarization-induced efflux of hypotaurine from mouse cortex slices: Comparison with taurine and GABA. Life Sci. 29, 811-816.

Kubota Y., Inagaki S., Kito S., and Wu J.-Y. (1987) Dopaminergic axons directly make synapses with GABAergic neurons in the rat neostriatum. Brain Res. 406, 147-156.

Lisowsky D. R., Norenberg L. O. B., and Norenberg M. D. (1986) Effect of ammonia on cyclic AMP production in primary astrocyte cultures. Brain Res. 386, 386-388.

Lux H. D., Loracher C., and Neher E. (1970) The action of ammonium on postsynaptic inhibition of cat motoneurones. Exp. Brain Res. 11, 431-447.

Maddison J. E., Leong D. K., Dodd P. R., and Johnston G. A. R. (1990) Plasma GABA-like activity in rats with hepatic encephalopathy is due to GABA and taurine. Hepatology 11, 105-110.

Malminen O. and Kontro P. (1986) Modulation of the GABA-benzodiazepine receptor complex by taurine in rat brain membranes. Neurochem. Res. 11,8594.

Martin D. L., Madelian V., Seligmann B., and Shain W. (1990) The role of osmotic pressure and membrane potential in $\mathrm{K}^{+}$-stimulated taurine release from cultured astrocytes and LRM55 cells. I. Neurosci. 10, 571-577.

Medina J. H. and De Robertis E. (1984) Taurine modulation of the benzodiazepine- $\gamma$-aminobutyric acid receptor complex in brain membranes. J. Neurochem. 42, 1212-1217.

Namima M., Okamoto K., and Sakai Y. (1983) Modulatory action of taurine on the release of GABA in cerebellar slices of the guinea pig. J. Neurochem. 40, $1-9$.

Norenberg M. D. (1981) The astrocytes in the liver disease, in Advances in Cellular Neurobiology (Fedoroff S. and Hertz L., eds.), vol. 2, pp. 303-352, Academic Press, New York.

Norenberg M. D., Mozes L. W., Papendick R. E., and Norenberg L. O. B. (1985) Effect of ammonia on glutamate, $\gamma$-aminobutyric acid and rubidium uptake by astrocytes. Ann. Neurol. 18, 149.

Oja S. S. and Kontro P. (1983) Taurine, in Handbook of Neurochemistry (Lajtha A., ed.), vol. 3, 2nd ed., pp. 501-533, Plenum Press, New York.

Okamoto K. and Namima M. (1978) Uptake, release and homo- and heteroexchange diffusion of inhibitory amino acids in guinea-pig cerebellar slices. J. Neurochem. 31, 1393-1402.

Pappas S. C., Ferenci P., Schafer D. F., and Jones E. A. (1984) Visual evoked potentials in rabbit model of hepatic encephalopathy. II. Comparison of hyperammonemic encephalopathy, postictal coma and coma induced by synergistic neurotoxins. Gastroenterology 86, 546-551.

Pasantes-Morales H. and Schousboe A. (1989) Release of taurine from astrocytes during potassium-evoked swelling. Glia 2, 45-50.

Pitkänen R. I., Korpi E. R., and Oja S. S. (1985) Cerebral cortex slices in sodiumfree medium: Depletion of synaptic vesicles. Brain Res. 326, 384-387.

Pluta R. and Albrecht J. (1984) Thioacetamide-induced hepatic encephalopathy in the rat. Clinical observations. Neuropat. Pol., 22, 379-385.

Raabe W. (1989) Ammonium decreases excitatory synaptic transmission in cat spinal cord in vivo. J. Neurophysiol. 62, 1461-1473. 
Reid M. S., O'Connor W. T., Herrera-Marschitz M., and Ungerstedt U. (1990) The effects of intranigral GABA and dynorphin A injections on striatal dopamime and GABA release: Evidence that dopamine provides inhibitory regulation of striatal GABA neurons via $\mathrm{D}_{2}$ receptors. Brain Res. 519, 255260.

Sakai Y., Okamoto K., and Kimura H. (1985) Pharmacological evidence for taurine as an inhibitory neurotransmitter in the cerebellum, in Taurine: Biological Aspects and Clinical Perspectives (Oja S. S., Ahtee L., Kontro P. and Paasonen M. K., eds.), pp. 313-319, Alan R. Liss, New York.

Shain W., Madelian V., Martin D. L., Kimelberg H. K., Perrone M., and Lepone R. (1986) Activation of $\beta$-adrenergic receptors stimulates release of an inhibitory transmitter from astrocytes. J. Neurochem. 46, 1298-1303.

Van Calker D. and Hamprecht B. (1981) Effects of neurohormones on glial cells, in Adances in Cellular Neurobiology (Federoff S. and Hertz L., eds.), vol. 1, pp. 36-67, Academic Press, New York.

Walz W. and Allen A. F. (1987) Evaluation of the osmoregulatory function of taurine in brain cells. Exp. Brain Res. 68, 290-298.

Zieve L. (1982) Hepatic encephalopathy, in Diseases of the Liver (Schiff L. and Schiff E. R., eds.), pp. 433-459, Lippincott, Philadelphia.

Zieve L. (1987) Pathogenesis of hepatic encephalopathy. Metab. Brain Dis. 3, 147165. 